\title{
Chinamitales: defensores y justicias k'ichee' en las comunidades indígenas del altiplano de Guatemala colonial
}

\author{
OWEN H. JONES \\ Southeast Missouri State University \\ ojones@semo.edu
}

\section{RESUMEN}

El presente articulo examina las funciones de los defensores indigenas cuya posición como lideres de parcialidades (chinamitales) en las sociedades kichee's existió en Mesoamérica precolombina y continuó hasta el siglo XIX colonial en Guatemala. Esta era una posición legal y administrativa que las élites en la sociedad k'iche'ana heredaban gracias a las conquistas militares de sus padres $y$ abuelos en la época precolombina. Los chinamitales defendieron a los habitantes de sus parcialidades, tanto a las élites como a los plebeyos, en las disputas de tierras y en casos criminales. Estas figuras persistieron en las comunidades indigenas desde el siglo XVI hasta el siglo XIX como defensores legales no reconocidos oficialmente, participando en tribunales en comunidades indigenas a nivel local $y$ defendiendo sus distritos ante los Cabildos indigenas. También actuaron en una capacidad similar al Cabildo indigena al producir testamentos, nominar candidatos para las elecciones del Cabildo y del convento, colectar tributo y escoger trabajadores para el repartimiento. Su defensa llegó a afectar procedimientos judiciales coloniales a nivel regional y de la Audiencia de Guatemala cuando surgian disputas sobre la adjudicación de tierras en comunidades indigenas y cuando percibian que el Cabildo indígena no estaba protegiendo sus intereses. Palabras clave: representación legal, mayas, Guatemala, kichee's, chinamitales 


\section{ABSTRACT}

The present article examines the functions of indigenous advocates whose position as ward leaders (chinamitales) in K'ichee' societies existed in Pre-Columbian Mesoamerica and continued into the colonial nineteenth century in Guatemala. This was a hereditary legal and administrative position that elites in K'ichee'an society enjoyed as a result and reward of military conquest in the Pre-Columbian era. Chinamitales advocated for the inhabitants of their wards who were both elites and non-elites in land disputes and in criminal matters. They persisted in indigenous communities from the sixteenth century to the nineteenth century as officially unrecognized legal advocates who participated in tribunals in indigenous communities at the local level and advocated for their constituents before their indigenous town councils. They also acted in a similar capacity as the indigenous municipal council, making last testaments, nominating candidates for local town council elections and positions in the church laity, collecting tribute, and choosing laborers for the repartimiento. Their advocacy spilled over into colonial judicial proceedings at the regional and high court levels when disagreements arose within indigenous communities over land disenfranchisement and whenever they sensed that the indigenous municipal council was not protecting their interests.

Keywords: legal representation, Mayas, Guatemala, K'ichee's, chinamitales 
U no de los cargos administrativos y judiciales más duraderos en la sociedad k'iche'ana desde tiempos precolombinos hasta fines de la época colonial en el siglo XIX fue el de chinamital, líder de una parcialidad de un pueblo. ${ }^{1}$ El chinamital era un miembro de la élite k'ichee', kaqchikel o tzutujil, de un linaje local galardonado con el liderazgo de una parcialidad después de la conquista de una municipalidad. ${ }^{2} \mathrm{Su}$ cargo y responsabilidad eran abogar para los macehuales (plebeyos) ${ }^{3}$ y principales que vivían en su barrio a cambio de su servicio laboral y

1 El término kichéano se refiere a uno de los grupos indígenas que forman las ramas del árbol lingüístico maya, el mismo que incluye a los k’ichee’s, a los kaqchikeles, a los tzutujiles, a los achíes, a los sapultecos y a los sipakapenses. Todos estos pueblos hablan idiomas que provienen de la misma raíz. La palabra chinamital proviene de los pipiles, quienes hablaban náhuat del sur, un idioma de la familia Uto-Azteca de la que procede el náhuatl, la lengua del centro de México. Para una discusión persuasiva de la difusión del náhuat por los pipiles en Guatemala véanse Campbell 1985a y 1985b.

2 Este ensayo utiliza el término kichee para representar tanto a la nación como a la lengua usada por ella. Esta es la forma reconocida por lingüistas como Sergio Romero (2015: xv), porque refleja la vocal prolongada usada en algunas palabras del idioma. El término kiche’ también está reconocido, pero no refleja la prolongación de la vocal común en el idioma k'ichee'. Quiché y kiche son maneras en que el término fue escrito por escribanos españoles e indígenas coloniales. He intentado seguir la ortografía k'ichee' que aparece en los documentos y que fue otorgada por fray Francisco de la Parra quien era el autor de la ortografía colonial de la lengua k'ichee' en el siglo XVI. En la ortografía colonial en k'ichee', el fonema «qh» representa el sonido «ch'» o «ch» con clausura glótica; el fonema «q,", una «q" con «,», representa el sonido «ts" o «ts» con clausura glótica; el fonema «x» representa el sonido "sh»; el fonema "E» representa el sonido "q" que es un "q" con clausura glótica; el fonema «f» representa el mismo sonido que «j» en espańol pero con más movimiento fricativo en el glotis; el fonema «u» $\mathrm{o}$ "V» antes y después de un vocal representa el sonido de «W»; el fonema «k" representa el sonido «k» con clausura glótica; el fonema "q" representa el sonido de "q" con clausura glótica; y, finalmente, el fonema «e’» representa el sonido de «e» con clausura glótica. En algunos casos cambié el tresillo «E» por el «q".

3 El término macehual es un préstamo del náhuatl. Se utiliza en la mayoría de lenguas mesoaméricanas y significa "plebeyo». Los españoles lo adoptaron como término reconocido y es tan común como la palabra cacique, préstamo del arawak del Caribe que significa «jefe». Los españoles adoptaron términos de lenguas de las Américas y los usaron en el léxico judicial, especialmente para referirse a instituciones y estructuras políticas y sociales. A veces, adoptaron palabras aunque tuvieran términos suficientes en español; por ejemplo, cacique en vez de «jefe», calpul en vez de "parcialidad» o «barrio», y macehual en vez de "plebeyo». Véase Haskett 1991: 133. 
recíproca lealtad. Sus títulos en k'ichee' incluían utzam chinamit (cabeza de la parcialidad), tzaq'al chinamital (defensor y líder de la parcialidad), k'amal be (líder, guía, agente de matrimonio y anciano respetado de la comunidad) у popol uinaq' (gente del petate o estera). ${ }^{4}$ Un título español, cabeza del calpul, basado en un préstamo del náhuatl, confirma la posición de cabeza del barrio. Era intercambiable con muchos de los términos k'ichee's ya mencionados. Los españoles lo usaron en su documentación para describir una institución que tenía similitud con el calpul de los nahuas de México central.

La presencia ubicua de esta organización de liderazgo en la litigación ante los magistrados españoles y criollos y su inclusión frecuente en documentos extrajudiciales o notariales escritos en k'ichee' evidencian la continuidad e influencia de estos personajes en las comunidades indígenas en el altiplano occidental de Guatemala. Varios estudiosos han identificado semejantes miembros de un gobierno básico en cada comunidad indígena que era contigua al Cabildo pero no autorizado, reconocido o ratificado por los oficiales coloniales en muchas de las sociedades indígenas de Latinoamérica colonial. ${ }^{5}$ Aunque aparecen frecuentemente en el registro legal, el sistema colonial nunca reconoció el conjunto de chinamitales como justicias y oficiales legítimos, ratificados por los oficiales coloniales en sus comunidades originales. Las autoridades coloniales en el siglo XVII hicieron excepciones para los cabezas de calpul y ejercían más tolerancia por estos líderes no reconocidos oficialmente que en el siglo XVIII, especialmente al final. En el siglo XVIII, los cabezas del calpul aparecen en el registro español como instigadores de rebeliones, defensores de sus barrios y testigos para sus comunidades pero sin la gravitas de los oficiales del Cabildo indígena

4 El petate o la estera fue un símbolo de matrimonio y de linaje. Era una metáfora para la familia, la tribu y la cama matrimonial que fue una estera o un petate. Significó y simbolizó la base de la sociedad y de la civilización k'iche’ana.

5 Gibson 1964: 182-183; Lockhart 1992: 36-37; y Haskett 1991: 199-200. Sobre los indígenas de Guatemala, véase Luján Muñoz 2011: 147-150; y Martínez Peláez 1994: 536-558. Por algunas sugerencias de un gobierno conjunto al Cabildo para los mayas de Yucatan, véase Restall 1997: 68-72. 
ni la preferencia de los magistrados y jueces españoles, y agitadores defendiendo sus privilegios y demandando que los magistrados espańoles los respetasen como caciques o jefes hereditarios. En documentos escritos en lenguas indígenas, los chinamitales conducen algunos de los asuntos de la comunidad y hasta elaboran testamentos en lugar de los oficiales del Cabildo; abogan en declaraciones de tierras, especialmente las que incluyen las cuentas de ejidos frente a los oficiales del Cabildo; y se muestran particularmente involucrados en proteger las tierras de la comunidad de cualquier forma de alienación.

Múltiples chinamit (barrio, cantón, parcialidad) constituían las unidades básicas de la organización social de cada tinamit amaq' (pueblo, nación) k'iche’ano. Robert M. Hill II y John Monaghan definen esta unidad social como una comunidad en sí misma, equivalente al calpul del México central. Aunque el chinamit estaba conformado por linajes principales que gobernaban a los sujetos plebeyos, ambos grupos no se hallaban necesariamente relacionados por vínculos de sangre. Los chinamit demuestran la continuidad de esta unidad cooperativa desde tiempos precolombinos hasta fines de la época colonial, así como su transformación al sistema de cantones o parcialidades tal como se practica en Sacapulas, en la Guatemala contemporánea. ${ }^{6}$ Para Hill y Monaghan es difícil identificar cómo los linajes principales llegaron a ejercer el liderazgo del chinamit, aunque mencionan la posibilidad de un sistema feudal y sugieren que el barrio pudo haber sido entregado en premio a los linajes señoriales y de élite a cambio de su servicio militar a los príncipes y reyes de la confederación k'ichee'. Robert Carmack, un antropólogo cuyo trabajo resulta fundamental para el estudio etnohistórico de los k'ichee's, define el chinamit y el kalpul (intercambiable con calpul) como dos unidades territoriales distintas. ${ }^{7}$ Hill y Monaghan no están de acuerdo con las conclusiones de Carmack y definen ambos conceptos como intercambiables. En este artículo, se les considera tal como Hill y Monaghan los han descrito.

6 Hill y Monaghan 1987.

7 Carmack 2001a: 213-223. 
Los tres autores mencionados en el párrafo anterior reconocen y analizan estas instituciones como unidades colectivas, pero no profundizan en el cargo de liderazgo hegemónico y la defensa que estos líderes —las élites de los barrios_ - practicaban a nombre de sus clientes plebeyos y principales. Las únicas excepciones son, primero, el tratamiento de los calpules que ofrece Hill en una edición revisada de su libro y, segundo, un artículo del mismo autor publicado anteriormente. ${ }^{8}$ Dicho ensayo es su discusión más actualizada sobre los chinamitales en la sociedad k'iche'ana, la misma que incluye los casos de Sacapulas, Tecpan y San Miguel Totonicapán. Hill resalta la desaparición y desintegración de los chinamitales en algunas comunidades, las diferencias en municipalidades multiétnicas y barrios que fueron el resultado de la política de congregación en un pueblo, y la proliferación y el éxito de líderes de barrios en otras comunidades. Algunos de los historiadores guatemaltecos de la colonia en Guatemala han destacado la posición de calpul y se los han conectado a los privilegios de caciques. Jorge Luján Muñoz enfatiza lo que Pedro Cortés y Larraz describió en la Descripción geográfico-moral de la diócesis de Goathemala, que «los calpules y principales son los maestros de la ley y que nada se hacía sin su consentimiento». ${ }^{9}$ Su descripción argumenta que los calpules y principales concertaban matrimonios, se dirigían al común de sus pueblos, colectaban tributo y actuaban como oráculos, curanderos y conservadores de tradiciones prehispánicas. De una manera similar argumenta el historiador guatemalteco Severo Martínez Peláez, excepto que condena a los cabezas del calpul considerándolos explotadores de los plebeyos. ${ }^{10} \mathrm{Mi}$ discusión de los chinamitales se centra en cómo actuaron como defensores y catalizadores del común (miembros de la comunidad cuyos intereses se volcaban en un pleito y que aparecían en actos judiciales para expresar sus opiniones), tanto en casos coloniales españoles como en documentos producidos en la lengua k'ichee' por sus propias comunidades y para ellas. También, exploro

8 Hill 2001: 198-200 y 1989.

9 Luján Muñoz 2011: 140-150. Véase también Cortés y Larraz 1958.

${ }^{10}$ Martínez Peláez 1994: 536-558 y 2011: 81-101. 
cómo los chinamitales tomaron el lugar de los oficiales del Cabildo en la producción de la documentación notarial escrita en k'ichee'.

Desde 1523 hasta 1825, los chinamitales fueron protectores de las tierras de la comunidad, tanto las comunales como las privadas, ejerciendo un rol de liderazgo como defensores de sus parcialidades. Además, nominaron a otros miembros de la élite de su barrio y a sí mismos como candidatos para los puestos del Cabildo y el servicio laico religioso. Estos cargos fueron conferidos en elecciones anuales y un chinamital podía servir en estos sin perder su estatus en el barrio porque era hereditario. Estas elecciones a veces causaron muchas facciones en una comunidad entre los chinamitales de las parcialidades distintas. Estos líderes decidieron quiénes de entre los macehuales de su barrio trabajarían en proyectos de obras públicas y en labores conectadas con el repartimiento. ${ }^{11}$ Antes de las imposiciones propias del colonialismo español, los chinamitales también recolectaron el tributo y lo enviaron a sus señores de la confederación k'ichee.. ${ }^{12}$ Su influencia se traducía en poder.

Los chinamit o calpul fueron considerados como pequeñas unidades de un total. Por ejemplo, según el Título de Tamub, fechado en septiembre de 1812 pero copiado de un documento más temprano, dentro de la confederación k'ichee', Uwila, el topónimo k'ichee' para Chichicastenango, era el séptimo chinamito calpul de Utatlan o Q'umarkaaj. Uwila era gobernado por un chinamital con el título de $A g$ Uwila, «él que es señor de Chichicastenango». Es comúnmente aceptado que los señores de los estados mayas prehispánicos eran nombrados con esa fórmula y que estaban asociados a la ciudad-estado sobre la que presidian. ${ }^{13}$

${ }^{11}$ Para la discusión más reciente del continuo repartimiento durante toda la época colonial en la América Central, véase Patch 2013.

12 «Título de los Seńores de Qustaaltenango y de Momostenango firmado por el conquistador Don Pedro de Alvarado, con una reseña de la historia del Quiché, de las historias del Rey Q'ikab, de la conquista de la ciudad de Quetzaltenango por los Españoles, etc., Títulos de los antiguos nuestros antepasados los que ganaron estas tierras Otzoya, antes que viniera la Fe de Jesu Christo entre ellos, en el año de mil y trescientos». Archivo General de Centro América [en adelante AGCA], A.1, leg. 6074, exp. 54883.

${ }^{13}$ Iannone, Houk y Schwake 2016: 11. 
El término «chinamital» como sustantivo que significó «parcialidad» era intercambiable con la persona que fuera líder de ella dependiendo del contexto durante toda la época colonial.

En títulos tempranos como el Título de los Señores de Qustaaltenango y de Momostenango, los cabezas del calpul o líderes del barrio, la parcialidad o el cantón capitanean a sus guerreros durante la batalla en conquistas para ayudar a aumentar la confederación k'ichee'. Los chinamitales mandaron sus propias milicias en guerra debajo del mandato de un capitán príncipe prehispánico antes de la conquista española, la misma que fue posible gracias a la ayuda de tropas indígenas auxiliares. ${ }^{14}$ Estos personajes participaron aun después de la conquista española en campañas militares para incorporar comunidades en regiones no conquistadas al sistema español, como las reducciones del manche chol, lacandón y de los tzendales o tzeltales de Chiapas en $1712 .{ }^{15}$ Después de ser conquistados, fueron relocalizados en comunidades, a veces como barrios o chinamit, en pueblos previamente conquistados y colonizados. Las habilidades de los chinamitales para organizar milicias entre los sujetos de sus barrios continuaron cuando el sistema colonial necesitó tropas auxiliares para reducir comunidades indígenas hostiles o para pacificar a los «indios

14 «Título de los Señores de Qustaaltenango y de Momostenango». AGCA, A.1, leg 6074, exp. 54883. Para una descripción más amplia y detallada de conquista en la época posclásica prehispánica, véase Akkeren 2007. Véase, además, «Título Uchabaja». AGCA, A.1 5936, exp. 51914, f. 19, que trata de la conquista mediante metáforas k'ichee's de la tierra de los Toltecatl tomada por los k'ichee's (también transcrito en Carmack 1973: 370). Véase también Akkeren 2000: 99-100.

15 "Título de Gobernador del pueblo de Xela a don José de Goméz Tih indio principal de dicho pueblo", 15 de octubre de 1712. AGCA, A1.24, leg. 1579, exp. 10223, f. 324. Don José de Goméz Martin Tih era un indio principal de San Francisco el Alto que recibió el puesto de gobernador del municipio de Xelaju como recompensa por dirigir a un régimen de tropas auxiliares para pacificar la rebelión de los Tzeltales en Chiapas en 1712 («Los papeles de los Jucub», A1, Leg. 5967, Exp. 52381). Antes de 1712, participaba en el Cabildo indígena de Xelaju como regidor y alcalde segundo y ordinario, aunque era de San Francisco el Alto (Akkeren 2007: 27; y AGCA, A1.20, leg. 1503, exp. 9983, f. 225r). Su apellido Tij fue un diminutivo de Tijeran, un nombre reconocido que pertenecía a un linaje de caciques y chinamitales, una gran casa (nim $j a)$, fundadores de Xelaju de las congregaciones en el siglo XVI. 
bravos» en diferentes partes de Guatemala. El primer término en el título para defensor en las parcialidades, tzaq'al chinamital, se deriva de la raíz tzaq', que significa "fortaleza sobre un cerro" en k'ichee'. Esta conexión entre la protección y la guerra es relevante, pues los defensores estaban llamados a proteger los intereses de su gente. Está también relacionada al hecho de que los chinamitales capitaneaban los guerreros de su barrio o parcialidad durante la batalla. La litigación tomó el lugar de la guerra entre las municipalidades que ya habían sido incorporadas al imperio español con pocas excepciones.

El sistema colonial español reconocía los derechos de la nobleza hereditaria y concedió el estatus de cacique a quienes pudieran probar una conexión a los nim ja, «casas grandes», originales. Carmack analizó sintácticamente muchos de los términos relacionados con el liderazgo del pueblo k'iche'ano prehispánico y colonial; ${ }^{16}$ sin embargo, su esfuerzo de definición pasó por alto algunos términos y títulos superpuestos, así como el que los escribanos k'iche'anos jugaran mucho con el lenguaje y usaran pares semánticos para describir las cosas y conferir énfasis. ${ }^{17}$ En la documentación colonial producida hasta el siglo XIX temprano, los señores fueron reconocidos como tales y los gobernadores indígenas llevaban el título de chinamital en algunos testamentos de Rabinal. Los escribanos identificaron con este título a don Domingo Santeliz y a don Joseph Soloman, quienes fueron gobernadores de la municipalidad. ${ }^{18} \mathrm{Es}$ más probable que fueran chinamitales y gobernadores al mismo tiempo, porque el puesto de gobernador era conferido por oficiales españoles por un mandato limitado y el cargo de chinamital era hereditario, un puesto de por vida.

La defensa legal de los k'ichee' de la Guatemala colonial ocurrió en muchos niveles. En el nivel local, los tzaq'al chinamitales discutieron para mantener el control de los plebeyos y las tierras en una sola parcialidad.

${ }^{16}$ Carmack 2001a: 190-250.

${ }^{17}$ Carmack 2001a.

18 "A Collection of Wills and Other Legal Papers in Quiché, 1752 - 1778», The Latin American Library, Tulane University, Nueva Orleans, Luisiana, William Gates Collection, 497.281, Q6d2. 
En tanto miembros de la élite encomendados con la tarea de proteger paternalmente y maternalmente a los ral cual, «sus hijos», en el chinamit, protegieron los intereses de sus plebeyos, que eran sus propios intereses, ante las justicias y los jueces —aristócratas k'ichee's de los Cabildos elegidos - y el gobernador indígena — un oficial nombrado por los administradores españoles en cada pueblo_- El cargo de chinamital no los perjudicaba si habían sido nominados por sus semejantes para un puesto en el Cabildo o si un chinamital había recibido la responsabilidad del gobernador del pueblo. En teoría, un principal k'ichee' podía obtener un puesto en el Cabildo o como gobernador pero nunca iba a perder su cargo hereditario de chinamital. Por esta razón, si no funcionaba bien la aceptada rotación de cargos y puestos, se generaban muchos pleitos y facciones en las elecciones de cada pueblo. ${ }^{19}$ Los chinamitales también protegieron los intereses de las élites en sus barrios como qui ratz, «sus hermanos mayores», mostrando así una relación horizontal entre iguales antes que una relación vertical entre principal y plebeyo. ${ }^{20}$

Los argumentos de su defensa legal rara vez aparecieron en registros regionales y administrativos coloniales; menos aún en el registro k'ichee'. Era más común detectar esta defensa en documentación en castellano presentada ante un magistrado español en audiencias regionales, especialmente cuando los chinamitales o cabezas de calpul se volvían incómodos para el oficio colonial. Sin embargo, estos defensores de las parcialidades tenían un poder considerable. Representaron la voz de la mayoría en su barrio, la de aquellos que eran los más vulnerables a la explotación administrativa. Sus acciones, antes que sus palabras, aparecen con frecuencia en la documentación en k'ichee' y español.

En su Recordación Florida, Tomo I, escrita en la década de 1690 como una historia general de Guatemala, el capitán don Francisco Antonio de Fuentes y Guzmán explica cómo la ley funcionaba en la confederación

\footnotetext{
19 Thompson 2000.

${ }^{20}$ Carmack 2001a: 100-101. En la «Petición vuc ahau presidente», el escribano demuestra deferencia al alcalde mayor por llamarse a sí mismo yn alcual la, in criado la’ ahau, "yo soy su hijo, yo soy su criado, Señor». The Latin American Library, Tulane University, Nueva Orleans, Luisiana, Rare Book Case, 497.281, P487.
} 
k'ichee' del siglo XV. El autor menciona en muchos puntos el calpul como una unidad, una parcialidad conectada a través del linaje. ${ }^{21}$ Lo que Fuentes y Guzmán no explica es que el liderazgo de la parcialidad se conectaba por un linaje élite, no así todo el barrio. Los líderes fueron considerados los calpules o ah calpul, «el que es la cabeza de la parcialidad». Según Fuentes y Guzmán, el calpul era el responsable de pagar por los crímenes de sus súbditos en caso de robo si era la primera ofensa y solo si el ladrón era un miembro rico del barrio. Una mujer casada, aunque fuese joven o viuda, ya no estaba sujeta a su propio calpul sino que pasaba a formar parte del calpul de su marido. En los casos de profanación de lo sagrado, todo el calpul podía ser esclavizado por la segunda ofensa. ¿Quién tenía realmente la protección del calpul? Aquellos miembros de la élite que se consideraban calpules o chinamitales. Era su defensa paternal la que importaba. Era el imperativo del plebeyo obedecer, como un niño obedece a sus padres.

La mayoría de documentos de Guatemala escritos en español y en lenguas indígenas omiten los deberes de los calpules o chinamitales. No obstante, estos pueden ser inferidos. Un contrato en español entre oficiales indígenas y Gabriel Mateo Maldonado, del 7 de mayo de 1688 -el mismo que involucró derechos de agua y la creación de un sistema hidráulico que traería agua a la plaza central de Quetzaltenangomenciona la participación de varios principales en la producción del documento, llamándolos "cavesas de calpul». Se declara que ellos aparecen en nombre de los demás principales, tatoque (señores, gobernantes, miembros de la élite), y el común del pueblo. ${ }^{22}$ Parte del contrato involucró la concesión de veinticinco trabajadores nativos por semana, con sus azadones, hachas y machetes, para ayudar a excavar y habilitar un

\footnotetext{
${ }^{21}$ Fuentes y Guzmán 2012.

22 Protocolos de Quetzaltenango. AGCA, A1.20, leg. 3057, exp. 29329, f. 75v. El término tatoque es un préstamo del náhuatl o náhuat. El término náhuatl es tlatoque (señor, gobernante, principal, de élite), lo cual incluye el enclítico «tl». Se requiere más investigación sobre si en k'ichee' se usó este término antes de la conquista española o si fue uno de los términos que los españoles introdujeron por su legalismo. En esta instancia particular, el alcalde mayor usa el término como par semántico de "principal» porque significa lo mismo. No es un grupo distinto del de los principales.
} 
camino para el agua; otros diez en caso de que se necesitaría la mano de obra adicional; y el acuerdo de que no se les pagaría por su labor. Veinte pesos se pagarían por adelantado. Todos los gastos, adjuntos alojamiento y comida, estaban incluidos. El saldo del pago total de doscientos pesos y ocho reales sería retenido hasta que el trabajo fuese completado y los oficiales indígenas estuviesen satisfechos con el mismo. Todos los alcaldes y regidores, el gobernador indígena y los cabezas del calpul tenían que estar de acuerdo en nombre de los tatoque y el común del pueblo. El contrato fue preparado y aceptado ante el corregidor y sus testigos. Los cabezas del calpul participaron en la creación de este documento porque tenían la responsabilidad de organizar el trabajo y escoger quienes de entre los plebeyos dejarían de prestar este servicio.

Un caso criminal de 1791 explica la defensa legal que ejercía el chinamital. En este, una ladina (residente hispanizada y aculturada de los pueblos indígenas) había vendido un alfalfal a un indio, Juan Ordońez, sin seguir los procedimientos legales pertinentes. ${ }^{23}$ Era usual y legalmente requerido que, antes de la venta, un pregonero anduviera por la calle para averiguar si había una objeción por cualquier persona que se opusiera a la transacción o tuviese derecho a la tierra. En esta venta, el pregón se había omitido. Por ello, ante la muerte del comprador indígena Juan Ordoñez, quien había legado el alfalfal a su hijo Lorenzo Ordoñez y a su yerno Crispin Presansit, el juez del caso quiso que la propiedad se vendiera por segunda vez. Los chinamitales se involucraron en este proceso porque querían proteger el derecho de Lorenzo y Crispin como propietarios de la tierra que Juan Ordońez había comprado a la ladina. El reporte del alcalde mayor de Totonicapán al fiscal de la Audiencia, fechado el 8 de noviembre de 1791, indica:

porque en el mismo día vinieron todo su calpul (calpul Señor es una parcialidad de cinco, que con este nombre tiene este Pueblo, y ha con su todo, y así para cada pleito se presenta un barrio que es un abuso arriesgado, e intolerable) y cabeza del calpul presentado es Manuel Sic y Francisco Quenón, los cuales con la más declarada insolencia me 
dijeron que de ninguna manera daban el alfalfal y porque les dije que los pondría presos, para que obedecieran me respondió dicho Manuel, que convocaría el Pueblo pues no permitían la devolución del solar. ${ }^{24}$

Usualmente, los chinamitales podían asegurar el apoyo de su parcialidad y utilizar la amenaza de su influencia sobre los plebeyos como un arma contra las autoridades coloniales, las otras parcialidades de su comunidad, los oficiales y justicias de sus cabildos y el gobernador indígena.

Para asegurar que sus órdenes fuesen obedecidas, el magistrado del caso nombró un gobernador indígena que garantizara la conformidad de todos los naturales de San Miguel Totonicapán. El Cabildo primero se resistió, pero después capituló en favor de la decisión del alcalde mayor. Solo tres individuos se opusieron al nombramiento: Pedro Morales y los dos chinamitales antes mencionados. Manuel Sic repitió muchas veces que no apoyaría el nombramiento del gobernador indígena y que dejaría de dar criados o ministros de su calpul para servir en el Cabildo o en el convento. Él podía hacer estas amenazas porque los chinamitales nominaban, de entre los nobles de su parcialidad y para las elecciones anuales de oficiales en pueblos indígenas, a los candidatos para servidores civiles y religiosos laicos. Ellos también designaban a otros chinamitales y principales de sus parcialidades para las elecciones a puestos cívicos en el Cabildo y a cargos religiosos laicos en la alcaldía de la iglesia que servían al aparato colonial. Los miembros del Cabildo votaban por alguno de los nombres nominados. Después de las elecciones en enero de cada año, los oficiales coloniales ratificaban a los electos. La amenaza de Manuel Sic demuestra el poder que tenían los chinamitales de cada parcialidad de los pueblos indígenas en sus comunidades. Su lucha era la de asegurar justicia para su facción; si lo lograban, tendrían el apoyo de las demás parcialidades. Su función principal era defender los derechos y privilegios de su calpul. Los chinamitales de las otras parcialidades defendían los de las suyas. La amenaza, en este caso, ejemplifica la negociación de hegemonía entre el orden colonial y la autoridad local, basada en 
la costumbre, que ejercían estos tres chinamitales. El reporte pidió la opinión del presidente de la Audiencia de Guatemala, quien respondió que castigar a los tres cabezas de calpul, alborotadores y rebeldes, además de a cuatro principales, serviría de ejemplo a quienes se opusiesen a la autoridad del Estado colonial.

Muchas veces los chinamitales fueron las causas de faccionalismo en las comunidades indígenas. Podían incitar la violencia y la usaron como una herramienta política. Los cabezas de calpul de San Francisco el Alto, según se registra en un documento del 29 de julio de 1696, se hacían presentes en la casa del Cabildo justo cuando los alcaldes de la comunidad habían juntado al común para recolectar el tributo real. ${ }^{25}$ Estos líderes exigían que los alcaldes les diesen el derecho de cobrar y colectar el tributo, amenazándolos con que si no se les permitía hacerlo, tomarían sus varas de justicia y nombrarían otros alcaldes para sustituirlos. Esta amenaza socavaba la autoridad de los magistrados del sistema colonial y ponía a los cabezas del calpul en la posición de amotinados y rebeldes contra las justicias de su pueblo. También se evidencia que los chinamitales reconocían que sus nominaciones constituían la base de las elecciones anuales de los justicias y los oficiales en el pueblo y que tenían el cargo de hacer políticamente poderosos a los miembros principales de su chinamit. El corregidor, quien había sido instrumental como teniente del alcalde mayor en evaluar por qué los indígenas de San Francisco el Alto no habían pagado el tributo, entró en la escena. Antes, el corregidor había comisionado al Cabildo indígena de San Miguel Totonicapán para tomar una declaración en k'ichee' del Cabildo de San Francisco el Alto. Esta declaración fue lo que incitó a los cabezas del calpul a actuar en contra de sus alcaldes. El corregidor los mandó llamar por ellos y más de cincuenta hombres llegaron a la casa del Cabildo con armas ocultas con las cuales planeaban aporrear al administrador colonial. En vez de incitarlos aún más, el corregidor decidió no reprenderlos ni castigarlos por la traición, la falta de respeto y la enorme molestia que le habían causado. En cambio, elevó los autos a su superior, el alcalde mayor. 
El mismo tipo de incitación y faccionalismo fue el motivo de un motín en Tecpan Atitlan en 1759, que llevó a los magistrados españoles a silenciar las voces de los chinamitales y a prohibirles defender los intereses de sus sujetos ante las autoridades españolas. ${ }^{26}$

En 1699, los chinamitales que representaban a varios sujetos de San Mateo Ixtatan presos en la cárcel del alcalde mayor en Huehuetenango declararon en un caso que involucró a cinco tributarios del pueblo, quienes rompieron las varas del mando de los dos alcaldes indígenas. ${ }^{27}$ Durante la refriega, los tributarios causaron que parte del tributo real recabado en la tercera porción de la fiesta de San Juan — doscientos cuarenta reales, equivalentes a treinta pesos, una suma considerable - se cayeran de los bolsillos de los alcaldes. Desafortunadamente, el testimonio de estos calpules no sobrevive porque fue desglosado de la información que constituyó la diligencia judicial y la petición en este caso. No podemos determinar si los chinamitales defendieron a los encarcelados o demandaron que se les enjuiciase por el crimen. Lo que sí queda en evidencia es que los chinamitales testificaban en causas criminales y defendían o demandaban a sus sujetos en sus barrios. Los prisioneros fueron sentenciados a treinta azotes cada uno y recibieron la pena de exilio al pueblito de Dolores de Lacandon en el estado mexicano actual de Chiapas.

¿En qué se basaba la legitimidad de los chinamitales? Estas autoridades eran la personificación hereditaria de la parcialidad y, como tales, recibían todos los beneficios y privilegios propios de su estatus. Un documento en la lengua k'ichee' sin fecha ni procedencia discute los derechos hereditarios de don Bartolomé Mejía como chinamital. Junto con él, Francisco Muñes, Francisco Hernández y Gaspar López Ztaq’uy elevaron una petición al alcalde ordinario de su pueblo. Los peticionarios declararon que su parcialidad y los plebeyos que eran parte de ella debían estar bajo el amparo de Francisco Mejía Pol, qui kahauh vae vinak, «su padre de esta gente». ${ }^{28}$ Evidentemente, Francisco Mejía Pol, el mayor, no era su

\footnotetext{
${ }^{26}$ Hill 1989: 186. Véase también Martínez Peláez 2011: 148-150.

27 "Causa Criminal fha contra diferenttes yndios del pueblo de San Matteo Ystattan», 1699. AGCA, A.1, leg. 2890, exp. 26634.

${ }^{28}$ AGCA, A3, leg. 2897, exp. 42993.
} 
padre biológico, sino su protector y defensor, una relación paternalista que sustentaba el derecho hereditario de ciertas élites que habían retenido esta prerrogativa gracias a las conquistas de sus padres y abuelos. La petición indica que are retaam are qui kahauf are pa qui mam ri tix topol... ta qo rahauarem qu rahauh qui mam, "está reconocido que sus padres y sus abuelos derramaron sangre en guerra, este es su reino de sus padres y abuelos». ${ }^{29}$ Tradicionalmente, sus antepasados habían defendido la posesión de tierras y abogaron contra los abusos reales o percibidos del Cabildo indígena. El documento afirma que are qu uae do Fran.co xuqaholaf canok, «así es que este don Francisco se le hizo su hijo permanentemente», que sugiere que no era su hijo biológico sino un hijo adoptado porque no tenía hijos hombres. ${ }^{30}$ La petición afirma que don Francisco Mejía Pol tenía cuatro hijas que no heredaron el chinamit. Francisco Mejía Pol, el hijo adoptado, era el padre biológico de Bartolomé Mejía y, a través de la retórica propia del título oficial, este último reafirmaba su posición. La cuestión central de su autoridad dependía de si su padre tenía el derecho hereditario a gobernar como chinamital de su parcialidad (chinamit) o no. Según la petición, Francisco Mejía Pol había sido adoptado en el linaje conquistador, un concepto aún mal entendido por historiadores de comunidades k'iche'anas. ${ }^{31}$ La petición afirma que:

\footnotetext{
${ }^{29} \mathrm{Ib}$.

${ }^{30} \mathrm{Ib}$.

${ }^{31}$ Para las sociedades indígenas en Mesoamérica, no hay nada escrito sobre el tema de la adopción en un linaje gobernante. Sin embargo, para los Iroquois de Norteamérica, las cinco naciones o tribus hacían un ritual de adopción de sus cautivos de guerra y, después de mucho tiempo, algunos de estos cautivos servían en posiciones de poder como, por ejemplo, capitán de guerra. Para una explicación más detallada, véase Richter 1992: 65-74. Si el proceso de adopción entre los k'ichee' era similar, puede que Francisco Mejía Pol haya sido un cautivo de guerra adoptado por el linaje de los chinamitales de la parcialidad en cuestión y que haya llegado a ser valorado. Es posible también que haya sido un plebeyo que demostró valor en la guerra y que haya sido adoptado por el linaje de élite de un chinamit por tal razón. Cabe notar que, en un documento se utiliza el término calel ah pop (AGCA, A3, leg. 2897, exp. 42993); Carmack (2001b) define calel como "príncipe» y ah pop como «rey». Es cierto que estos títulos en el posclásico tardío tenían un significado conectado a un rango militar. Si el chinamital era un capitán de guerra, es posible que el calel ah pop haya tenido un significado militar también.
} 
xaui caquighaohih u qo heye calpulil xaui cacah que el chupam calpulil rica qui bih truh qo u caredo Barome Mexia.
También ellos defienden su existencia y autoridad en los calpulis. También ellos nos dejaron en los calpulis. Ellos dicen que se le ofrecen a Bartolomé Mejía su cargo.
También defienden la existencia y autoridad de Don Bartolomé en los calpulis. También los del linaje conquistador nos dejaron en los calpulis. Dicen que le ofrecen a Bartolomé Mejía su cargo. ${ }^{32}$

Esta petición es un raro ejemplo de cómo un defensor noble de los plebeyos y la élite de su parcialidad se basaron en documentos de este tipo para asegurar su posición ante los justicias del pueblo. Se trataba de una comunicación interna entre dos niveles de defensa en una comunidad k'ichee'. Uno protegía a los plebeyos y las élites de un barrio ante el Cabildo y el otro defendía al pueblo de los abusos de los oficiales coloniales españoles y criollos.

En el pueblo achí de Rabinal, los deberes del chinamital solo se pueden derivar del contexto de ciertos documentos notariales. En una relación de la carrera de don Domingo Santeliz, desde que fue elegido alcalde ordinario hasta que le nombraron al cargo de gobernador indígena, los chinamitales aparecen como defensores importantes de las tierras tradicionales de la comunidad cuando estas corrieron el riesgo de ser enajenadas o vendidas a miembros de otros calpules o a personas ajenas a la comunidad. La cuenta del año 1757, indica que Domingo Santeliz compró una porción de tierra irrigada por Zaneeb, una montaña venerada por los Rabinaleb como un espacio sagrado. Se trata precisamente de la cima de la montaña Zamaneb en donde, en el Popol Wuj, los Rabinaleb esperan su «alba» y el principio de su reino en Kajyub (Cerro Rojo). La cuenta refiere que:

${ }^{32}$ AGCA, A3, leg. 2897, exp. 42993. En las citas, dejo una traducción literal del k'ichee' en la columna del medio para que el lector pueda ver la construcción del lenguaje. Como argumenta Frederic Jameson (1972), una lengua no se aprecia en una traducción porque pierde su valor por el cambio de significado y de referentes de una lengua a otra. Sergio Romero (2015) también usa una traducción literal para demostrar el uso del idioma k'ichee'. 
uae chicut zcaq'in chic haam uleu chuvi zaneeb chi chahanibal chi quech chinamital tzihabab uinaq' chi cah labuh 24 tts tostt chi zucul chuach Dios xaui q'qui chuculal, uae uleu mix q'atzibah xи loq' chiui. este otro pues [él compró] una pequeña tierra irrigada encima de Zamaneb con el apoyo de estos ante de los oradores por la gente, los chinamitales por veinticuatro tostones en verdad ante Dios. También, éstos son aquellos que los asentarán [los mojones] en esta tierra. Nosotros lo acabamos de escribir que la compró aquí.
[El gobernador Don Domingo Santeliz compró] una pequeña tierra irrigada encima de Zamaneb con el apoyo de los chinamitales. En verdad ante Dios, [Don Domingo Santaliz] con veinte y cuatro tostones la compró ante los chinamitales, los que defienden a su gente. También, los chinamitales asentarán [los mojones] en esta tierra. En esta, nosotros lo acabamos de escribir que la compró. ${ }^{33}$

Tres chinamitales fueron convocados cuando, justo antes de su muerte, el padre cura fray Francisco Toscano compró un solar y la casa en él construida para un ladino. Como lo refiere la cuenta del año 1770:

\begin{abstract}
Macut xquibantah consentir común principal q(ue)ge mix callix ui pacab uae Alc.e ordinario Domingo Santeliz qhe Mixulos ui chi ju uinac lahuh tostones Mix u llaa uae Dom.o Santeliz chi suculic locoh Mix u ban uae Alc.e chirech cut padre cura tzalix ui uae
\end{abstract}

Ellos, pues, no la permitían la asamblea de principales. Así que nosotros la acabamos de observar aquí en la posesión de este alcalde ordinario Domingo Santeliz. Así que él la compró aquí por treinta tostones. Él la dio, este Domingo Santeliz, en verdad, la hizo la compra. Él la hizo este alcalde de su padre cura, pues, él lo
La asamblea de principales no la permitían [la compra del solar y la casa para un ladino]. Entonces, Don Domingo Santeliz por treinta tostones lo acaba de comprar de la cura fray Miguel Salazar. Así que nosotros la acabamos de observar aquí en la posesión del alcalde ordinario, Domingo Santeliz. Él acaba de hacer una

33 «Santalis Papers», William Gates Collection of Quiché Source Materials; MSS 279; William Gates Papers; L. Tom Perry Special Collections; 20th Century Western \& Mormon Manuscripts; 1130 Harold B. Lee Library; Brigham Young University; Provo, Utah 84602; http://sc.lib.byu.edu/ Box 96 - 4, ff. 6-7. 
chuch cah tij ${ }^{34}$ cura regresó aquí este dinero Frai Mig.l Salazar. a nuestra madre, nuestro maestro la cura fray Miguel Salazar. verdadera compra. Este alcalde regresó el dinero a fray Miguel Salazar, cura y nuestro maestro. ${ }^{35}$

El común o asamblea no oficial que se juntaba cuando había que tomar decisiones de importancia estaba compuesto por principales de Rabinal. Ellos demandaron que el dinero que se había pagado por la casa y solar del fraile difunto fuera devuelto a la comunidad, alegando además que el gobernador indígena tenía la responsabilidad de comprarlos. Pablo Reyes, Pedro Alvarado y Agustín Alvarado fueron los chinamitales involucrados que firmaron sus nombres al pie del documento. Eran miembros del común de principales que se oponían a que las tierras se alienasen de la Municipalidad.

El común en pueblos indígenas no consistía necesariamente de los plebeyos de la comunidad sino de personas de esta que tenían interés en una causa. Se juntaban en la casa del Cabildo, en la casa real del alcalde mayor o corregidor, y brindaban su voz y su opinión a la litigación local y regional. Como muchas veces los chinamitales participaron en el común, este era el vehículo de su participación en los asuntos de justicia del Cabildo, de su pueblo y de la región.

Los testamentos de Rabinal registran la mano de los chinamitales que actuaron como defensores y testigos en la creación de estos documentos en las casas de los testadores, tal y como lo hacían los justicias y oficiales

${ }^{34} \varepsilon \mathrm{a}$ chuch $\varepsilon a h$ tij es un título de respeto en la lengua k'ichee' que significa «nuestra madre, nuestro maestro" y se deriva de un título concedido a todos los oficiales y justicias del pueblo ea chuch cahau, «nuestra madre, nuestro padre». El mismo vincula a los oficiales con los ancestros de la comunidad y explica su cargo, en tanto protectores de los intereses del pueblo, como si sus miembros fueran sus hijos. Dado que los frailes no se casaban, no podían conectarse con los ancestros de la comunidad. Por tanto, se les llamaba «nuestra madre, nuestro maestro» en señal de respeto por su cargo oficial y su liderazgo en la comunidad.

35 «Santalis Papers», William Gates Collection of Quiché Source Materials; MSS 279; William Gates Papers; L. Tom Perry Special Collections; 20th Century Western \& Mormon Manuscripts; 1130 Harold B. Lee Library; Brigham Young University; Provo, Utah 84602; http://sc.lib.byu.edu/ Box 96 - 4, ff. 24-25. 
del Cabildo. ${ }^{36}$ Los chinamitales también participaron en la producción independiente de testamentos en diversas ocasiones. De los cincuenta y nueve testamentos de Rabinal, veintidós implicaron su participación como testigos o como autoridades responsables de la elaboración de estos. Así, el testamento de Manuel Xpattaq', producido el 12 de mayo de 1766, incluyó las firmas de dos notarios que no se presentaron como escribanos del Cabildo. Las autoridades presentes incluyeron tres chinamitales: Francisco Tzullen, Nicolás Garnica y Diego Raxcaco. Ellos capturaron el casliquil tzij o "palabras vivas» del testador sin que tuviese presente ningún justicia del Cabildo ni ningún oficial de la alcaldía mayor. Los chinamitales siempre fueron principales que pertenecían al grupo de los que llegaban a ser gobernadores indígenas de Rabinal. ${ }^{37}$

El 22 de febrero de 1747, las justicias de Rabinal se reunieron para producir un documento en el cual testificaron que sus antepasados habían tomado posesión de las tierras que ahora ellos consideraban propias. Aunque se encontró entre los testamentos de Rabinal, no es propiamente un testamento. El documento es una relación de los mojones del territorio propio y de los chinamitales que controlaban tierras específicas. Se puede notar cómo las palabras chinamital y calpul

${ }^{36}$ "A Collection of Wills and Other Legal Papers in Quiché, 1752 - 1778», The Latin American Library, Tulane University, Nueva Orleans, Luisiana, William Gates Collection, 497.281, Q6d2.

${ }^{37}$ Aunque podríamos generalizar y sugerir que todos los gobernadores indígenas nombrados por oficiales coloniales españoles en Guatemala fueron chinamitales, el que estuviesen nombrados y no fuesen oficiales electos por la comunidad indígena indicaría que no. Si todos los gobernadores nombrados fuesen chinamitales, entonces las autoridades espańolas hubieran seguido las costumbres tradicionales de los indígenas, pero no sucedió así en cada provincia. En Guatemala, los oficiales españoles escogían al gobernador de cada pueblo. Rabinal y los demás pueblos de las Verapaces en Guatemala eran distintos porque los frailes dominicos conquistaron a los indígenas con la paz y la religión. En esta provincia, los nativos estuvieron sujetos a los dominicos, quienes favorecían y protegían a los indígenas en las Verapaces de los abusos de los oficiales coloniales e intercedían por ellos ante el alcalde mayor y sus tenientes. Es posible que los frailes dominicos influyeran a los oficiales coloniales para que nombrasen a los gobernadores que querían los principales indígenas de los pueblos, pero no tenemos evidencia que lo mismo sucediese en otras provincias en Guatemala. 
son intercambiables entre sí y con la parcialidad y los líderes principales de la misma. El documento ejemplifica la naturaleza intercambiable de estos términos porque su escribano usa los dos en el texto. El escribano comienza con los siguientes enunciados:

\begin{abstract}
Chirech u bixic hun cayb $\varepsilon a$ tzih $\varepsilon a$ pixab chiquivach e ca chuch ca cahau ahauab al.c just.as gov.or principales oh juchob chi chinamitales chuvi retamaxic uae ox banelic uleu cachahim cuxtabal quech $\varepsilon a$ mam $\varepsilon a$ cahau tequcnib uinae cuc e cal ca cahol quehe cu mandar chiquech ahauab al.cdes chi co chinamitales calpules u chuch $u$ eahau ral $u$ cahol chu molah chu chobah quehe cu retamaxic chi u chahim cahcah mojones chi jutac tzobahichal uae uleu.
\end{abstract}

En esta se declara dos o tres de nuestras palabras, nuestras admoniciones ante ellos, ellos nuestras madres, nuestros padres señores, alcaldes, justicias, gobernador y principales. Nosotros somos los repartidores en los chinamitales. Aquí se lo aprenderán. Estos tres creadores de tierras, ellos lo guardaron en sus corazones. Nuestros antepasados (nuestros abuelos, nuestros padres) fueron gente conquistada como son ellos, estos nuestra progenie (nuestros hijos de una mujer, nuestros hijos de un hombre). Por lo tanto, era mandado para nosotros los señores, jueces que están en los chinamitales calpules su madre y padre, su hijo e hija, les guiarán. Los estará entendido, pues, se los reunirá, se los contará a y encaminará a nuestros mojones en cada milpa plantada de esta tierra.
Aquí se declara dos o tres de nuestras palabras, nuestras admoniciones de los repartidores en los chinamitales, ante ellos quienes son nuestras madres y nuestros padres, los señores, los alcaldes, las justicias, el gobernador y los principales. Aquí será aprendido. Estos tres creadores de tierras, ellos guardaron [la memoria de los mojones] en sus corazones. Nuestros antepasados fueron gente conquistada como son estos nuestra progenie. Por tanto, no fue comandado nosotros los señores, jueces que estamos en los chinamitales y calpules. Somos sus madres y padres y les guiáramos. Nuestros hijos e hijas los conocerán (sus mojones). Les reuniremos y los contaremos y encaminaremos a nuestros mojones en cada milpa plantada de esta tierra. ${ }^{38}$ 
Los chinamitales, nombrados como los justicias, hicieron la peregrinación para visitar los mojones: Francisco Cauee era el chinamital de Ortiz y Pantulul; Jacinto Sic o Jacinto cohom controlaba las tierras en Xalcata y Chirax; y Gaspar y Leonardo Pérez eran los chinamitales que dominaban Caq Ja y Bentana. Todos eran nombres de tierras relacionadas a Rabinal. Este documento fue copiado del archivo del Cabildo indígena de dicho pueblo el 8 de julio de 1779 por Gaspar Toh, quien se declaró copista de la página original de 1745 escrita por Joseph Toh, rech oxnelic uleu quech chinamitales rumal quehe qui tzonobal chinuvach yn ah tzib rech cavido, "para la división en tres partes de sus tierras, los chinamitales, porque así, ellos me lo pidieron a mí, el escribano del Cabildo». ${ }^{39}$ Los cabezas del calpul o chinamitales fueron los guardianes de tierras colectivas como los ejidos y de tierras privadas de los de su calpul o chinamit.

A menos que surgiese un conflicto entre la gente de un pueblo, los administradores y los magistrados coloniales solían ignorar a los chinamitales como líderes de sus comunidades con frecuencia. Aun así, existía la posibilidad de que los casos vistos por estos defensores y otros líderes locales de los barrios o parcialidades no llegasen a oídos de estos magistrados. Esto sucedía cuando los chinamitales intervenían activamente en situaciones que causaban problemas y faccionalismo en una comunidad y, por tanto, eran percibidos como quebrantadores de la paz que los oficiales coloniales esperaban que existiese. El asesinato violento de Diego Chixoy, un principal y líder de la Municipalidad, en el pueblo k'ichee' de Santa María Chiquimula en 1802, produjo una investigación detallada en 1805 que incluyó a tres alcaldes mayores de Totonicapán, Huehuetenango y Sololá, así como al corregidor de Quetzaltenango. La declaración de la esposa del difunto llevó a la detención de varios individuos, incluso muchos principales de Santa María Chiquimula. Tres de ellos confesaron haber cometido el asesinato y recibieron la pena de muerte; muchos otros fueron encarcelados como sospechosos porque habían tenido una disputa con el difunto Diego Chixoy, miembro de una

39 "A Collection of Wills and Other Legal Papers in Quiché, 1752 - 1778", The Latin American Library, Tulane University, Nueva Orleans, Luisiana, William Gates Collection, 497.281, Q6d2. 
facción. Un motín dos años antes del homicidio en Santa María Chiquimula había sido sofocado con la ayuda e influencia del difunto. Algunos lo querían; muchos otros lo odiaban. En una nota sobre la prisión de un año y siete meses que sufrieron muchos principales sospechosos, el fiscal abogado de la Real Audiencia de Nueva Guatemala comentó:

Otro si: dice el Fiscal: que por la lectura de este proceso entiende que en el pueblo de Chiquimula hay cierta especie de partidos, o bandos, a que los indios llaman CALPULES, dirigidos y gobernados sin duda por el mayor de las familias, los que tienen tanta autoridad como los mismos justicias, y son muy bien obedecidos que erogue siendo pues un mal principio de libertad o independencia para estar el pueblo sujeto a aquellas cabezas revolucionarias, sería muy conveniente cortar con oportunidad este vicio, sirviéndose prevenir Vuestra Alteza al Alcalde Mayor que con su acostumbrada sagacidad para no causar conmoción en el Pueblo, ponga en práctica los medios comunes a deshacer tales partidos y obligarlos a que a los únicos que deben respetar son a sus Alcaldes y Gobernador: comunicándosele esta providencia por acordado. ${ }^{40}$

El lenguaje de la nota sugiere que el fiscal acababa de recibir la noticia de que este nivel de liderazgo indígena existía, aunque la institución hubiese estado presente desde el siglo XV, según Fuentes y Guzmán. ${ }^{41}$ Los chinamitales usualmente pasaban desapercibidos a estos oficiales reales, quienes no se percataban de estos defensores o los ignoraban mientras no se inquietara la paz y se pagara el tributo a tiempo.

El mismo fiscal abogado de la Audiencia también señaló sobre el instigador principal de la revolución en Chiquimula: «que Miguel Soe u gi $\varepsilon a \varepsilon$ es el único que pensaba conmover el pueblo por ser como es el cabecera más antiguo, y que gobierna y domina no solo un calpul, sino los demás del pueblo». ${ }^{42}$ Esta afirmación sugiere que había diferentes niveles de cabezas del calpul en una comunidad. La edad y experiencia

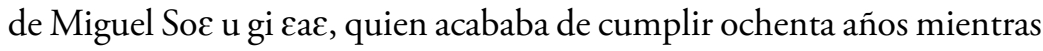
estaba en la cárcel, lo hacían tanto un anciano como un cacique. La comunidad debió respetarlo muchísimo.

40 "Contra varios yndios de Chiquimula por haver asesinado a Diego Chixoy». AGCA, A1.15, leg. 5476, exp. 47065, ff. 68v-69r

${ }^{41}$ Fuentes y Guzmán 2012.

${ }^{42}$ AGCA, A1.15, leg. 5476, exp. 47065. 
Un título similar viene de un ejemplo de principios del siglo XVII, proveniente de la documentación sobre un homicidio inusual cometido en San Miguel Totonicapán. El caso duró un año y medio. Se reveló que Martín García, una víctima hechizada, escupía sangre. García, sintiéndose al borde de la muerte, pidió a su familia que solicitara la presencia del gobernador y de los dos alcaldes del Cabildo para elaborar los autos y, especialmente, recoger el testimonio de su curandero, Diego Hernández. El documento preparado por el escribano el 1 de mayo de 1715 en la casa del Cabildo presentó el caso de la manera siguiente:

alcaldes, governador, regidores, escribano, ruq e uaq'chob chi calpules ruq chu ui chi Gr.a belezuy camiq ca q'aban rettal utzih uae rahpop ahtz'alam Bartolome Perez Ttiu chirech hun utz ytzel caya chirih ve q'atzih u suculiquil ue pumahay xahuna Dios e ttayom xaq'atta q'a xiquin oh justisia rumal cu ya u ttestigoyl uae Diego Ernandez chirih caq'a tto cu uae qui tzih chi q'a tzih chinimauachil publico chupam q'a Cabildo caq'aban ui uae enformasion chiquiuach e mas prinsipales are nabe tzih xare ui...
Los alcaldes, gobernador, regidores, escribano con los seis grupos en sus calpules con toda la familia Garcia Belazuy, aquí hacemos un señal de su palabra, este rahpop (orador en los linajes) y ah tzalam (juez de la parcialidad) Bartolome Perez Ttiu si sea buena o mala él la da aquí esta nuestra palabra su verdad, si sea la voluntad de Dios. Nosotros los oidores oíamos con nuestras orejas, nosotros las justicias. Porque pues él dará su testimonio este Diego Hernandez aquí. Nosotros escucharemos pues éstas, sus palabras en nuestra reunión pública a dentro de nuestro Cabildo. Nosotros hacemos esto aquí, esta información, ante todos los principales. Así que es la primera palabra aquí.
Los alcaldes, el gobernador, los regidores, el escribano, con los seis grupos en los calpules están aquí hoy con toda la familia García Belazuy y hacemos un registro de las palabras de este defensor en los linajes y juez de su parcialidad, Bartolomé Pérez Ttiu. Si sea buena o mala, él la da aquí en ésta nuestra palabra su verdad, si sea la voluntad de Dios. Nosotros las justicias y los oidores escuchábamos con nuestros oídos porque Diego Hernández da su testimonio aquí. Nosotros escucharemos sus palabras en nuestra reunión pública a dentro de nuestro Cabildo. Nosotros hacemos esta información aquí ante todos los principales. Así que es la primera palabra que da aquí. ${ }^{43}$

${ }^{43}$ AGCA, A.1, leg. 3024, exp. 29175. En k'ichee', rah significa «orador, defensor», y pop literalmente significa "petate o estera»; los k'ichee's, sin embargo, comúnmente usaron 
El título rahpop literalmente significa «orador o defensor en los linajes», y ah tźalam es un término para un «oficial judicial», un juez en las parcialidades. Estos títulos y posiciones pertenecen a los derechos y privilegios que tenía un principal en San Miguel Totonicapán para adjudicar tierras y resolver problemas domésticos entre las familias de su parcialidad, así como defender a sus subordinados ante el Cabildo. En su testimonio, Diego Hernández acusó a Bartolomé Pérez Ttiu, quien entonces era alcalde de la Cofradía de las Ánimas en San Miguel Totonicapán, de la maldición que llevaría finalmente al hechizado Martín García a su muerte.

El acusado era un juez en las parcialidades, lo que podría indicar un nivel adicional de atribuciones judiciales en las comunidades k'iche'anas. Es posible que el título de «ah tzalam» tuviese el mismo significado que el título principal «cabecera de los calpules» que aparece en la documentación legal en español. Un caso de Momostenango revela que antiguamente eran cuatro parcialidades en la municipalidad y que cada una tenía su alcalde o juez. Así, el fiscal de la Audiencia ordenó que se reconociese su poder siempre y cuando no fomentaran ninguna alteración del orden:

En Santiago Momostenango resultan de hacer parcialidades distintas de indios en aquel pueblo manteniendo cada una su Alcalde, juzga que V.S. puede mandar reconozcan dichas parcialidades a las justicias principales del Pueblo para cabeza sin formar cuerpos diversos en el proprio Pueblo y que si sobre el particular tuviesen algún privilegio lo manifiesten Guatemala y enero 23 de $1759 .{ }^{44}$

esta palabra como metáfora de linaje. Mi interpretación del término rah viene de la descripción del arte de fray Francisco Ximénez, O. P. (1985: 495). El mismo autor ofrece una interpretación de la palabra ah tz'alam: «Ah q,alam - nombre de dignidad, el señor que tiene trono y cárcel ah q,alama plur.[al]» [los escribanos k'ichee’s usaron el símbolo "q," para representar la fonema «tz’"] (Ximénez 1985: 67). Sobre el uso de la palabra pop como una metáfora de linaje, véase Akkeren 2000. Además, Carmack examina los términos ah tzalam y rahpop como aparecen en el Manuscrito de Totonicapán y refiere que ah tz’alam significa el escribano de la parcialidad. Rahpop está asociada con otros títulos que definen rango militar (2001b: 87-88).

44 «Diligencias Siguientes primero de los alcaldes del pueblo de Santiago Momostenango dio a entender...». AGCA, A.1, leg 2897, exp. 26778. 
Este pasaje indica que en Momostenango había parcialidades y que cada una tenía su alcalde, un juez que juzgaba en la parcialidad. Los oficiales coloniales querían que se reconocieran a las justicias del Cabildo del pueblo como sus líderes en vez de los diversos alcaldes de cada barrio. En cada municipalidad indígena de Guatemala existía un nivel de adjudicación tradicional como base de la sociedad en las parcialidades. Hubo jueces que adjudicaron en sus propios tribunales del barrio y aparecen en la documentación legal en español y en k’ichee'.

\section{A MODO DE CONCLUSIÓN}

Los chinamitales, calpules o cabezas de calpules eran más que meros agitadores del orden colonial. Ellos aparecieron en los registros españoles como perturbadores de la paz porque fueron un cuerpo de liderazgo básico en la sociedad k'iche'ana, aunque no fuese comprendido ni sancionado por la burocracia colonial española. Sus contrapartes fueron los chinames de los q'ekchi's y los molabes entre los mames en Guatemala, así como los ah cuch cabo'ob o a cux cabo de los mayas yucatecos, los jefes de los ayllus en los Andes y, en el centro de México, los calpuleque, tepixque o teuctli con funciones similares a las de los chinamitales. ${ }^{45}$ Entre el siglo XIII y el siglo XVI, los chinamitales sirvieron como capitanes militares, convocando a los guerreros a luchar por la expansión imperial aliada de la confederación k'ichee'. Sus funciones en los siglos XVII y XVIII se enfocaron menos en conquistar y más en defender los derechos y privilegios de sus parcialidades, cambiando la participación militar por la judicial en las repúblicas de indios bajo el imperio español. El chinamit o cabeza del calpul era un defensor de los intereses de la parcialidad sobre cuyo liderazgo tenía derecho hereditario. El término fue también intercambiable con el título de cacique. Hubo varios chinamitales que servían en el cargo y sus intereses fueron los del chinamit. Ellos fueron los abogados de sus pares en una relación

45 Hill 1989; y Patch 2002: 12-13. Para una descripción de las funciones prehispánicas y coloniales de los ah cuch cabo'ob o los a cux cabo, véase Quezada 2014. Para una descripción de los calpuleque y tepixque, consúltense Haskett 1991: 96; y Gibson 1964: 182-184. Para una explicación de los calpuleque, tepixque y teuctli, véase Lockhart 1992: $35-44$ y $103-105$. 
horizontal con otros principales en sus barrios, pero también defendieron a los plebeyos. Controlaron también la presentación de candidatos a los puestos oficiales del Cabildo y el servicio del convento. Estos chinamitales decidieron quiénes en su parcialidad cumplirían las obligaciones propias del repartimiento. Aseguraron que las tierras no se alienaran de sus barrios y comunidades y abogaron ferozmente para la conservación de sus derechos y terrenos. Fueron otro de los niveles de defensa dentro de la comunidad local y un consejo de ancianos que ejerció las funciones de los justicias del Cabildo en su ausencia. Los chinamitales estuvieron bajo el ah tzalam o juez de la parcialidad, quien adjudicaba casos en la parcialidad o barrio. Todos ellos fueron los protectores de los intereses de la comunidad y la base sobre la cual se erigió la sociedad k'iche'ana.

Pocas veces podemos descubrir las funciones administrativas y legales desde la perspectiva local, es decir, dentro de los pueblos y repúblicas de indios en América española. Los chinamitales se involucraron principalmente en las acciones legales de sus propias parcialidades y en la política intercomunal en procesos ventilados en el Cabildo indígena. El gobernador indígena o el Cabildo fueron usualmente los encargados de interactuar con la administración y el sistema legal colonial. Solo vemos la intervención de los chinamitales con la administración colonial cuando se presentaron conflictos con los oficiales y justicias de los cabildos de sus pueblos.

\section{BIBLIOGRAFÍA}

Akkeren, Ruud van. 2000. Place of the Lord's Daughter, Rab'inal, its history, its dancedrama. Leiden: Research School CNWS, Leiden University, School of Asian, African, and Amerindian Studies.

Akkeren, Ruud van. 2007. La visión indígena de la conquista. Ciudad de Guatemala: Serviprensa.

Campbell, Lyle. 1985a. "Appendix 1: Pipil and Other Varieties of Nahua». En Bossong, Georg y Wallace Chafe (eds.). The Pipil Language of El Salvador. Berlín: Mouton Publishers, 911-935. https://doi.org/10.1515/9783110881998.911

Campbell, Lyle. 1985b. "Appendix 2: Varieties of Nahua in Guatemala». En Bossong, Georg y Wallace Chafe (eds.). The Pipil Language of El Salvador. Berlín, Nueva York y Ámsterdam: Mouton Publishers, 936-942. https://doi. org/10.1515/9783110881998.936 
Carmack, Robert M. 1973. Quichean Civilization, The Ethnohistoric, Ethnographic, and Archaeological Sources. Berkeley: University of California Press.

Carmack, Robert M. 2001a. Kik'ulmatajem le kiche'aab'. Evolución del reino kiche'. Ciudad de Guatemala: Cholsamaj.

Carmack, Robert M. 2001b. Kik'aslemaal le K'iche'aab'. Historia Social de los K'ichés. Ciudad de Guatemala: Cholsamaj.

Cortés y Larraz, Pedro. 1958. Descripción geográfico-moral de la diócesis de Goathemala. Ciudad de Guatemala: Sociedad de Geografía e Historia de Guatemala, 2 tomos.

Fuentes y Guzmán, Francisco Antonio de. 2012. Recordación florida: Discurso historial y demostración natural, material, militar y politica del reyno de Guatemala. Ciudad de Guatemala: Universidad de San Carlos de Guatemala y Editorial Universitaria.

Gibson, Charles. 1964. The Aztecs Under Spanish Rule, A History of the Indians of the Valley of Mexico, 1519 - 1810. Stanford: Stanford University Press.

Haskett, Robert. 1991. Indeginous Rulers, An Ethnohistory of Town Government in Colonial Cuernavaca. Albuquerque: University of New Mexico Press.

Hill, Robert M., II. 1989. "Social Organization by Decree in Highland Guatemala». Ethnohistory. Vol. 36, núm. 2: 179-198. https://doi.org/ $10.2307 / 482277$

Hill, Robert M., II. 2001. Los Kaqchikeles de la época colonial, adaptaciones de los Mayas del altiplano al gobierno español, 1600 - 1700. Ciudad de Guatemala: Cholsamaj.

Hill, Robert M., II, y John Monaghan. 1987. Continuities in Highland Maya Social Organization: Ethnohistory in Sacapulas, Guatemala. Philadelphia: University of Pennsylvania Press.

Iannone, Gyles, Brett A. Houk y Sonja A. Schwake (eds). 2016. Ritual, Violence, and the Fall of the Classic Maya Kings. Gainesville: University Press of Florida.

Jameson, Frederic. 1972. The Prison-House of Language, A Critical Account of Structuralism and Russian Formalism. Princeton: Princeton University Press.

Lockhart, James. 1992. The Nahuas After the Conquest, A Social and Cultural History of the Indians of Central Mexico, Sixteenth Through Eighteenth Centuries. Stanford: Stanford University Press.

Luján Muñoz, Jorge. 2011. Ensayos de historia jurídica y del notariado en Guatemala. Ciudad de Guatemala: Academia de Geografía e Historia de Guatemala.

Martínez Peláez, Severo. 1994. La patria del criollo, ensayo de interpretación de la realidad colonial guatemalteca. Ciudad de México: Ediciones en Marcha.

Martínez Peláez, Severo. 2011. Motines de indios, la violencia colonial en Centroamérica y Chiapas. Ciudad de Guatemala: F\&G Editores.

Patch, Robert W. 2002. Maya Revolt and Revolution in the Eighteenth Century. Armonk: M. E. Sharpe. https://doi.org/10.4324/9781315702483 
Patch, Robert W. 2013. Indians and the Political Economy of Colonial Central America, 1670 - 1810. Norman: University of Oklahoma Press.

Quezada, Sergio. 2014. Maya Lords and Lordship, The Formation of Colonial Society in Yucatán, 1350 - 1600. Traducido por Terry Rugeley. Norman: University of Oklahoma Press.

Recinos, Adrián. 1957. Crónicas Indígenas de Guatemala. Ciudad de Guatemala: Editorial Universitaria.

Restall, Matthew. 1997. The Maya World, Yucatec Culture and Society, 1550-1850. Stanford: Stanford University Press.

Richter, Daniel K. 1992. The Ordeal of the Long-house, the Peoples of the Iroquois League in the Era of European Colonization. Chapel Hill: University of North Carolina Press.

Romero, Sergio. 2015. Language and Ethnicity among the K'ichee' Maya. Salt Lake City: The University of Utah Press.

Thompson, Philip C. 2000. Tekanto, a Maya Town in Colonial Yucatan. Nueva Orleans: Tulane University Middle American Research Institute.

Ximénez, Francisco, fray, O. P. 1985. Primera parte del Tesoro de las lenguas Cakchiquel, Quiche y Zutuhil, en que las dichas lenguas se traducen a la nuestra, española. Ciudad de Guatemala: Academia de Geografía e Historia de Guatemala.

Fecha de recepción: 27/VI/2016

Fecha de aceptación: 11/IX/2016 